\title{
Hydrothermal Synthesis and Tunable Multicolor Upconversion Emission of Cubic Phase $\mathbf{Y}_{2} \mathrm{O}_{3}$ Nanoparticles
}

\author{
Haibo Wang, ${ }^{1,2}$ Chao Qian, ${ }^{1}$ Zhigao Yi, ${ }^{1,2}$ Ling Rao, ${ }^{1,2}$ Hongrong Liu, ${ }^{1}$ and Songjun Zeng ${ }^{1}$ \\ ${ }^{1}$ College of Physics and Information Science and Key Laboratory of Low-Dimensional Quantum Structures and \\ Quantum Control of the Ministry of Education, Hunan Normal University, Changsha, Hunan 410081, China \\ ${ }^{2}$ Faculty of Materials, Optoelectronics and Physics, Key Laboratory of Low-Dimensional Materials and \\ Application Technology (Ministry of Education), Xiangtan University, Xiangtan 411105, China
}

Correspondence should be addressed to Songjun Zeng; songjunz@hunnu.edu.cn

Received 29 September 2013; Accepted 12 November 2013

Academic Editor: Jianhua Hao

Copyright (C) 2013 Haibo Wang et al. This is an open access article distributed under the Creative Commons Attribution License, which permits unrestricted use, distribution, and reproduction in any medium, provided the original work is properly cited.

\begin{abstract}
Highly crystalline body-centered cubic structure $\mathrm{Y}_{2} \mathrm{O}_{3}$ with lanthanide $(\mathrm{Ln})$ codopants $\left(\mathrm{Ln}=\mathrm{Yb}^{3+} / \mathrm{Er}^{3+}\right.$ and $\left.\mathrm{Yb}^{3+} / \mathrm{Ho}^{3+}\right)$ has been synthesized via a moderate hydrothermal method in combination with a subsequent calcination. The structure and morphology of $\mathrm{Y}(\mathrm{OH})_{3}$ precursors and $\mathrm{Y}_{2} \mathrm{O}_{3}$ nanoparticles were characterized by $\mathrm{X}$-ray diffraction and transmission electron microscopy. The results reveal that the $\mathrm{Y}_{2} \mathrm{O}_{3}$ nanoparticles possess cubic phase and form the quasispherical structure. The upconversion luminescence properties of $\mathrm{Y}_{2} \mathrm{O}_{3}$ nanoparticles doped with different $\mathrm{Ln}^{3+}\left(\mathrm{Yb}^{3+} / \mathrm{Er}^{3+}\right.$ and $\left.\mathrm{Yb}^{3+} / \mathrm{Ho}^{3+}\right)$ ions were well investigated under the $980 \mathrm{~nm}$ excitation. The results show that the $\mathrm{Yb}^{3+} / \mathrm{Er}^{3+}$ and $\mathrm{Yb}^{3+} / \mathrm{Ho}^{3+}$ codoped $\mathrm{Y}_{2} \mathrm{O}_{3}$ nanoparticles exhibit strong red and light yellow upconversion emissions, respectively. It is expected that these $\mathrm{Y}_{2} \mathrm{O}_{3}$ nanoparticles with tunable multicolor output and intense red upconversion emission may have potential application in color displays and biolabels.
\end{abstract}

\section{Introduction}

In the last few years, upconversion (UC) nanoparticles have attracted great attention in many research areas owing to their unique antistokes emission processes of converting a longer wavelength radiation to short wavelength emission [1-3]. Lanthanide-doped rare-earth oxides and related materials are common phosphors in optical display devices and fluorescent bioimaging applications [4-12].

$\mathrm{Y}_{2} \mathrm{O}_{3}$, as one of the most important rare-earth materials, was considered as an ideal candidate for biological applications, because of their higher mechanical, thermal, and chemical stability [13-15]. Rare-earth oxides were usually synthesized by thermal decomposition of their oxysalt precipitates such as hydroxide and oxalate at a certain temperature [16-19]. However, the thermal decomposition method requires high temperature and inert gases protection, resulting in complex experimental operations. Therefore, it is of significant importance to develop a simple method for the preparation of rare-earth oxide nanoparticles. Recently,
Ln-doped $\mathrm{Y}_{2} \mathrm{O}_{3}$ shows great potential application in optical display and lighting [20]. So, further investigations of tunable multicolor $\mathrm{UC}$ emission $\mathrm{Y}_{2} \mathrm{O}_{3}$ nanoparticles via codoping $\mathrm{Ln}$ ions $\left(\mathrm{Yb}^{3+} / \mathrm{Er}^{3+}\right.$ and $\left.\mathrm{Yb}^{3+} / \mathrm{Ho}^{3+}\right)$ are still of great interest. Up to now, there are many researches to regulate the multi-color output of UC nanomaterials via doping rare-earth ions [2125]. For example, Garry's group have reported that $\mathrm{Yb}^{3+}, \mathrm{Er}^{3+}$, $\mathrm{Ho}^{3+}$, and $\mathrm{Tm}^{3+}$ codoped $\mathrm{Y}_{2} \mathrm{O}_{3}$ nanocrystals can generate red, green, blue, and white light [25]. However, to the best of our knowledge, few studies have focused on the synthesis of spherical-like $\mathrm{Y}_{2} \mathrm{O}_{3}$ nanoparticles with tunable multicolor UC emissions by using facile hydrothermal method.

In this paper, different $\mathrm{Ln}^{3+}\left(\mathrm{Yb}^{3+} / \mathrm{Er}^{3+}\right.$ and $\left.\mathrm{Yb}^{3+} / \mathrm{Ho}^{3+}\right)$ ions codoped $\mathrm{Y}(\mathrm{OH})_{3}$ nanosheets have been successfully synthesized based on a facile and mild hydrothermal method. And the cubic phase $\mathrm{Y}_{2} \mathrm{O}_{3}$ nanoparticles were calcinated from these $\mathrm{Y}(\mathrm{OH})_{3}$ precursors. In addition, the UC luminescence properties of the $\mathrm{Y}_{2} \mathrm{O}_{3}$ doped with different $\mathrm{Ln}$ ions $\left(\mathrm{Yb}^{3+} / \mathrm{Er}^{3+}\right.$ and $\left.\mathrm{Yb}^{3+} / \mathrm{Ho}^{3+}\right)$ were investigated under $980 \mathrm{~nm}$ 
excitation. The UC mechanism and CIE (Commission Internationale del'Eclairage 1931 chromaticity) chromaticity coordinates were studied in detail.

\section{Experimental}

$\mathrm{Y}\left(\mathrm{NO}_{3}\right)_{3} \cdot 6 \mathrm{H}_{2} \mathrm{O} \quad(99.99 \%), \quad \mathrm{Er}\left(\mathrm{NO}_{3}\right)_{3} \cdot 6 \mathrm{H}_{2} \mathrm{O} \quad(99.99 \%)$, $\mathrm{Yb}\left(\mathrm{NO}_{3}\right)_{3} \cdot 5 \mathrm{H}_{2} \mathrm{O}(99.99 \%)$, and $\mathrm{Ho}\left(\mathrm{NO}_{3}\right)_{3} \cdot 5 \mathrm{H}_{2} \mathrm{O}(99.99 \%)$ were purchased from Sinopharm Chemical Reagent Co., Ltd (China). All other chemical reagents are of analytical grade and used directly without further purification.

2.1. Synthesis of Different $\mathrm{Ln}^{3+}$ Codoped $\mathrm{Y}_{2} \mathrm{O}_{3}$ Nanoparticles. $\mathrm{Y}(\mathrm{OH})_{3}$ nanosheets were synthesized by a facile hydrothermal method [26, 27]. For a typical protocol, $1 \mathrm{mmol}$ (total amounts) of $\operatorname{Ln}\left(\mathrm{NO}_{3}\right)_{3}(\mathrm{Ln}=\mathrm{Y}, \mathrm{Yb}, \mathrm{Er}$, and $\mathrm{Ho})$ with designed molar ratio (Y: Yb:Er $=78: 20: 2$ and $\mathrm{Y}: \mathrm{Yb}: \mathrm{Ho}=$ $78: 20: 2$ ) was added into $20 \mathrm{~mL}$ deionized water. And then the obtained solution was rapidly adjusted to $\mathrm{pH}=14$ by adding $10 \mathrm{wt} \% \mathrm{NaOH}$ solution. The obtained mixture was then transferred into a $50 \mathrm{~mL}$ stainless Teflon lined autoclave and reacted at $120^{\circ} \mathrm{C}$ for $12 \mathrm{~h}$. After reaction, the system was naturally cooled to room temperature. The resulting products were collected, washed several times with de-ionized water to remove residual $\mathrm{NaOH}$, and then dried at $80^{\circ} \mathrm{C}$ for $3 \mathrm{~h} . \mathrm{Y}_{2} \mathrm{O}_{3}$ nanoparticles were synthesized by sintered $\mathrm{Y}(\mathrm{OH})_{3}$ precursor at $500^{\circ} \mathrm{C}$ for $6 \mathrm{~h}$.

2.2. Characterizations. X-ray powder diffraction (XRD) patterns were recorded by using a D/max 2500/PC system X-ray diffractometer at $40 \mathrm{kV}$ and $250 \mathrm{~mA}$ using $\mathrm{Cu} \mathrm{K} \alpha$ radiation $(\lambda=1.5406 \AA)$. The morphology and size of the samples were characterized by transmission electron microscopy (TEM, JEOL-2100F) equipped with an Oxford's energy dispersive $\mathrm{X}$-ray spectroscopy (EDS). The UC emission spectra were recorded by a spectrophotometer ( $R$ 500) equipped with $980 \mathrm{~nm}$ laser diode as the excitation source. The digital photographs of the as-prepared samples were taken by a commercial digital camera (Canon 650D).

\section{Results and Discussion}

3.1. Crystal Phase and Morphology Analysis. The phase composition of the as-prepared $\mathrm{Y}_{2} \mathrm{O}_{3}: \mathrm{Yb} /$ Er was investigated by $\mathrm{XRD}$ analysis. As shown in Figure 1, the samples present characteristic diffraction peaks centered at $20.60^{\circ}(211), 29.32^{\circ}$ (222), $33.90^{\circ}$ (400), $36.08^{\circ}$ (411) $39.96^{\circ}$ (332), $43.62^{\circ}$ (134), $48.72^{\circ}$ (440), $53.44^{\circ}$ (611), $56.38^{\circ}$ (541), $57.88^{\circ}$ (622), $59.30^{\circ}$ (136), $60.72^{\circ}(444), 64.76^{\circ}(127), 71.28^{\circ}(800)$, and $72.52^{\circ}$ (811), which is matched well with the standard body-centered cubic $\mathrm{Y}_{2} \mathrm{O}_{3}$ (JCPDS card no. 88-1040). In addition, no other impurity diffraction peaks are observed, indicating that pure cubic phase nanoparticles were synthesized with good crystallinity and a homogenous $\mathrm{Y}-\mathrm{Yb}$ solid solution structure was formed.

To reveal the morphology and structure, the as-prepared samples were characterized by TEM (Figure 2). The asprepared $\mathrm{Y}(\mathrm{OH})_{3}: \mathrm{Yb} / \mathrm{Er}$ by hydrothermal method at

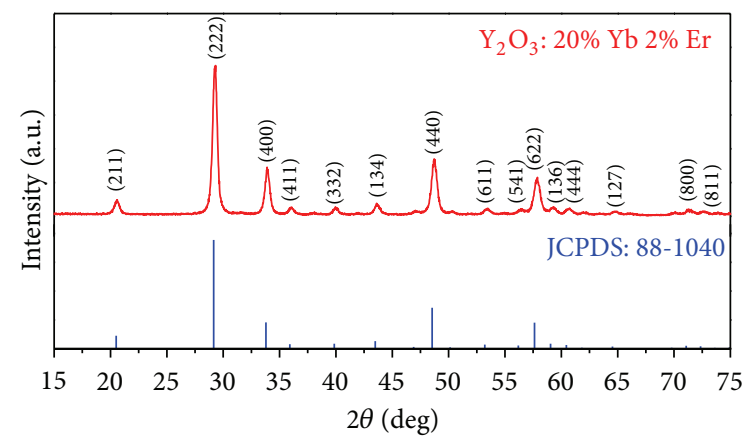

FIGURE 1: Typical XRD patterns of the $\mathrm{Y}_{2} \mathrm{O}_{3}: \mathrm{Yb} / \mathrm{Er}$ samples and the standard cubic phase $\mathrm{Y}_{2} \mathrm{O}_{3}$ (JCPDS: 88-1040).

$120^{\circ} \mathrm{C}$ for $12 \mathrm{~h}$ consists of nanosheet and frizzy nanosheet (Figure 2(a)). $\mathrm{Y}_{2} \mathrm{O}_{3}: \mathrm{Yb} / \mathrm{Er}$ calcinated from the precursor of $\mathrm{Y}(\mathrm{OH})_{3}: \mathrm{Yb} / \mathrm{Er}$ at $500^{\circ} \mathrm{C}$ for $6 \mathrm{~h}$ present agglutinate structure of sphere-like nanoparticles (Figures 2(b) and 2(c)). As shown in Figure 2(d), the obvious lattice fringes in the high resolution transmission electron microscopy (HRTEM) images confirm the high crystallinity of the as-prepared $\mathrm{Y}_{2} \mathrm{O}_{3}: \mathrm{Yb} / \mathrm{Er}$ nanoparticles. The interplanar distances between the adjacent lattices were measured to $2.64 \AA$, matching well with the $\mathrm{d}_{400}$ spacing of the cubic phase $\mathrm{Y}_{2} \mathrm{O}_{3}$ (JCPDS 88-1040). From the above results, we can see that rare-earth hydroxides are unstable compounds. When the temperature reached a certain value, the nanosheet and frizzy nanosheet hydroxides were burnt to stable sphere-like nanoparticles. During the TEM measurement, the elemental components of the $\mathrm{Y}_{2} \mathrm{O}_{3}: \mathrm{Yb} / \mathrm{Er}$ nanoparticles were detected by EDS. The sphere-like nanoparticles are mainly composed of $\mathrm{Y}, \mathrm{Er}$, $\mathrm{Yb}$, and $\mathrm{O}$, indicating that the doped $\mathrm{Yb}^{3+}$ and $\mathrm{Er}^{3+}$ were successfully incorporated into the $\mathrm{Y}_{2} \mathrm{O}_{3}$ host (Figure 2(e)). It is noted that the signals of $\mathrm{Cu}$ are attributed to the TEM copper grid.

3.2. Upconversion Luminescence Properties. It is well known that multicolor UC luminescence can be achieved by doping various sensitizers and active Ln ions. Here, we discuss the $\mathrm{UC}$ luminescence properties of $\mathrm{Y}_{2} \mathrm{O}_{3}$ nanoparticles through codoping $\mathrm{Yb}^{3+} / \mathrm{Er}^{3+}$ and $\mathrm{Yb}^{3+} / \mathrm{Ho}^{3+}$ ions. Under $980 \mathrm{~nm}$ excitation, the corresponding UC luminescence spectra and the proposed energy transfer mechanism are shown in Figure 3. As demonstrated in Figure 3(a), the UC spectra of $\mathrm{Y}_{2} \mathrm{O}_{3}: \mathrm{Yb} / \mathrm{Er}$ nanoparticles show the characteristic $\mathrm{Er}^{3+} \mathrm{UC}$ emissions including the green emission peaks $(522 \mathrm{~nm}$ and $541 \mathrm{~nm}$ ) and the red emission peak centered at $660 \mathrm{~nm}$. More importantly, it can be seen that the $\mathrm{Y}_{2} \mathrm{O}_{3}: \mathrm{Yb} /$ Er nanoparticles possess significant stronger red luminescence at $660 \mathrm{~nm}$, which is different from previously reported $\mathrm{NaYF}_{4}$ host that is usually presenting green UC emission [28]. Figure 3(c) shows the energy level diagram of the possible energy transfer processes between $\mathrm{Yb}^{3+}$ and $\mathrm{Er}^{3+}$. With absorbing $980 \mathrm{~nm}$ photon, the $\mathrm{Yb}^{3+}$ is excited to the ${ }^{2} \mathrm{~F}_{5 / 2}$ energy level and then transfers its energy to the nearby $\mathrm{Er}^{3+}$ ion. Immediately 


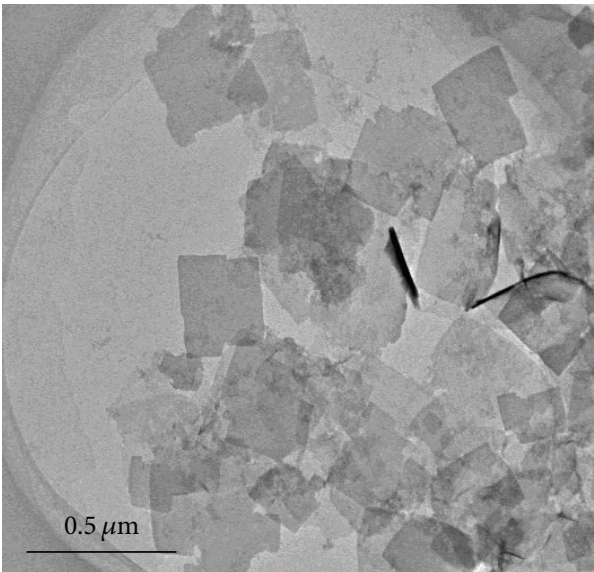

(a)

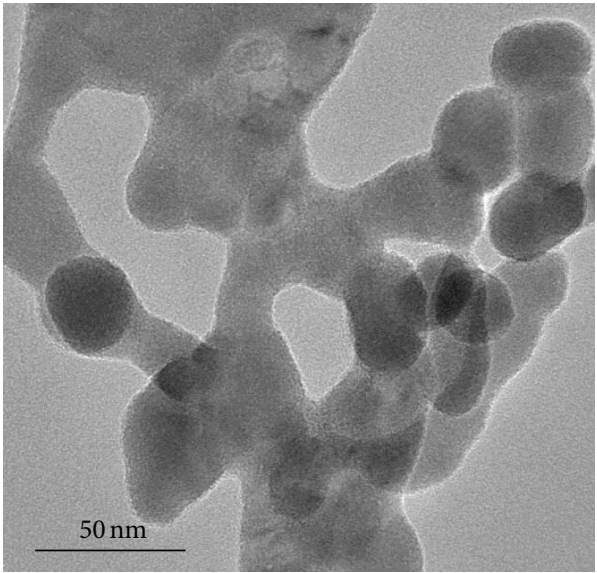

(c)

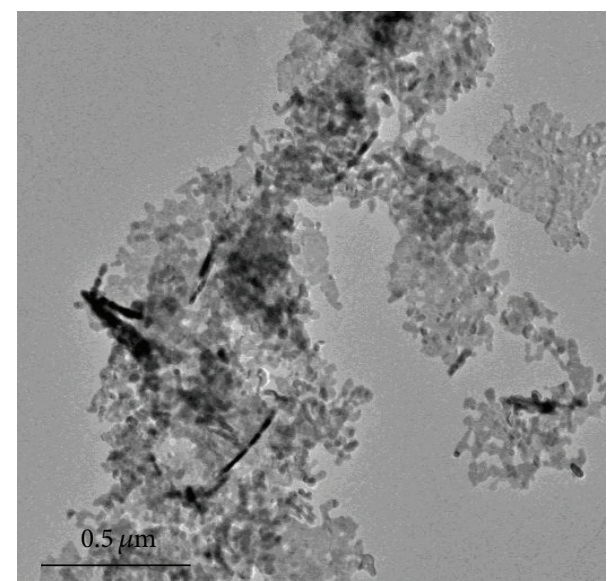

(b)

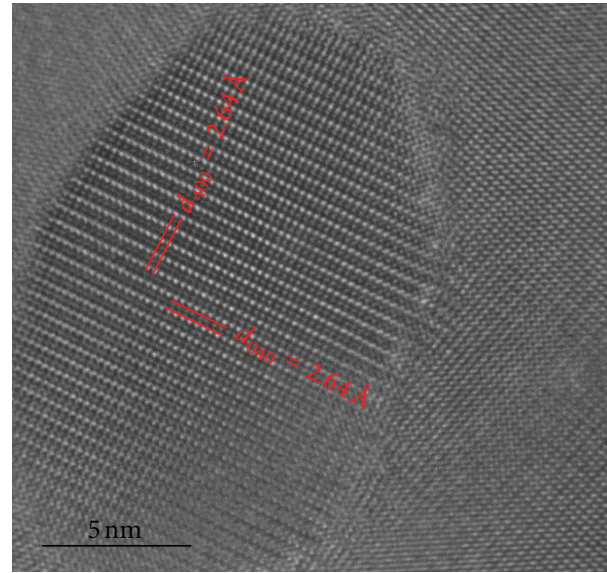

(d)

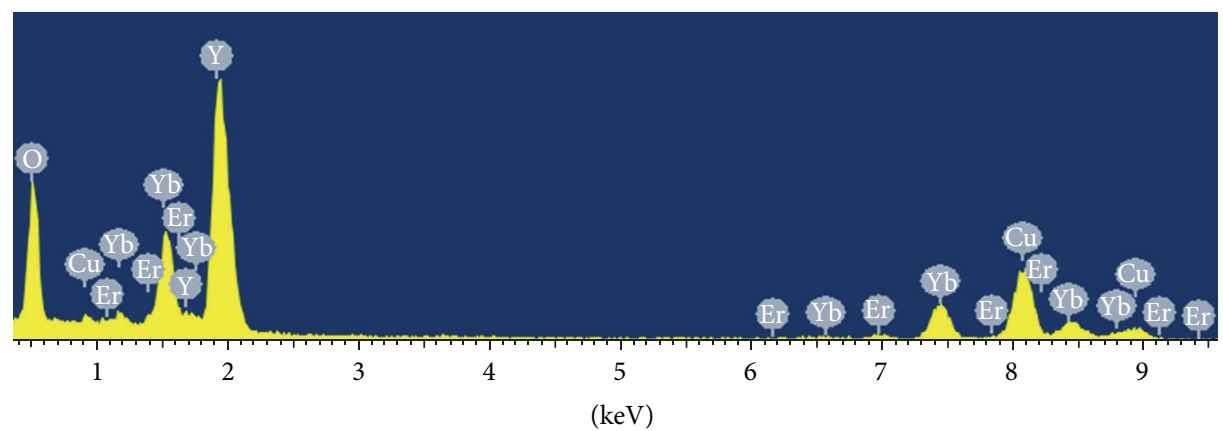

(e)

FIGURE 2: (a) TEM image of $\mathrm{Y}(\mathrm{OH})_{3}: \mathrm{Yb} /$ Er precursor; (b) low-magnification and (c) high-magnification TEM images of $\mathrm{Y}_{2} \mathrm{O}_{3}: \mathrm{Yb} / \mathrm{Er}$; (d) the HRTEM image of $\mathrm{Y}_{2} \mathrm{O}_{3}: \mathrm{Yb} / \mathrm{Er}$; (e) EDS of the $\mathrm{Y}_{2} \mathrm{O}_{3}: \mathrm{Yb} /$ Er nanoparticles (mainly composed of $\mathrm{Y}, \mathrm{Er}, \mathrm{Yb}$, and $\mathrm{O}$ elements).

following excited state absorption, transfer of energy from excited state $\mathrm{Yb}^{3+}$ resulted in populating the ${ }^{4} \mathrm{~F}_{7 / 2}$ state of $\mathrm{Er}^{3+}$. The excited state $\left({ }^{4} \mathrm{~F}_{7 / 2}\right)$ electrons of $\mathrm{Er}^{3+}$ nonradiatively relax to the ${ }^{2} \mathrm{H}_{11 / 2},{ }^{4} \mathrm{~S}_{3 / 2}$, and ${ }^{4} \mathrm{~F}_{9 / 2}$ levels $\left(\mathrm{Er}^{3+}\right)$. With high $\mathrm{Yb}^{3+}$-doped concentration, the green emissions are almost quenched and the intensity ratio of the red to the green emission is large, which results in strong red emission [29]. The dominant red UC emission is mainly attributed to the two energy-transfer processes ${ }^{4} \mathrm{~S}_{3 / 2}\left(\mathrm{Er}^{3+}\right)+{ }^{2} \mathrm{~F}_{7 / 2}\left(\mathrm{Yb}^{3+}\right)$ $\rightarrow{ }^{4} \mathrm{I}_{13 / 2}\left(\mathrm{Er}^{3+}\right)+{ }^{2} \mathrm{~F}_{5 / 2}\left(\mathrm{Yb}^{3+}\right)$ and ${ }^{4} \mathrm{I}_{13 / 2}\left(\mathrm{Er}^{3+}\right)+{ }^{2} \mathrm{~F}_{5 / 2}$ $\left(\mathrm{Yb}^{3+}\right) \rightarrow{ }^{4} \mathrm{~F}_{9 / 2}\left(\mathrm{Er}^{3+}\right)+{ }^{2} \mathrm{~F}_{7 / 2}\left(\mathrm{Yb}^{3+}\right)[25,29,30]$. The three emission peaks around at $522 \mathrm{~nm}, 541 \mathrm{~nm}$, and $660 \mathrm{~nm}$ can be assigned to the ${ }^{2} \mathrm{H}_{11 / 2} \rightarrow{ }^{4} \mathrm{I}_{15 / 2}$ (green), ${ }^{4} \mathrm{~S}_{3 / 2} \rightarrow$ ${ }^{4} \mathrm{I}_{15 / 2}$ (green), and ${ }^{4} \mathrm{~F}_{9 / 2} \rightarrow{ }^{4} \mathrm{I}_{15 / 2}$ (red) transitions of $\mathrm{Er}^{3+}$, respectively. As demonstrated in Figure $3(\mathrm{~b})$, the relative intensity of green $\left({ }^{5} \mathrm{~S}_{2} /{ }^{5} \mathrm{~F}_{4} \rightarrow{ }^{5} \mathrm{I}_{8}\right)$ to $\operatorname{red}\left({ }^{5} \mathrm{~F}_{5} \rightarrow{ }^{5} \mathrm{I}_{8}\right)$ 


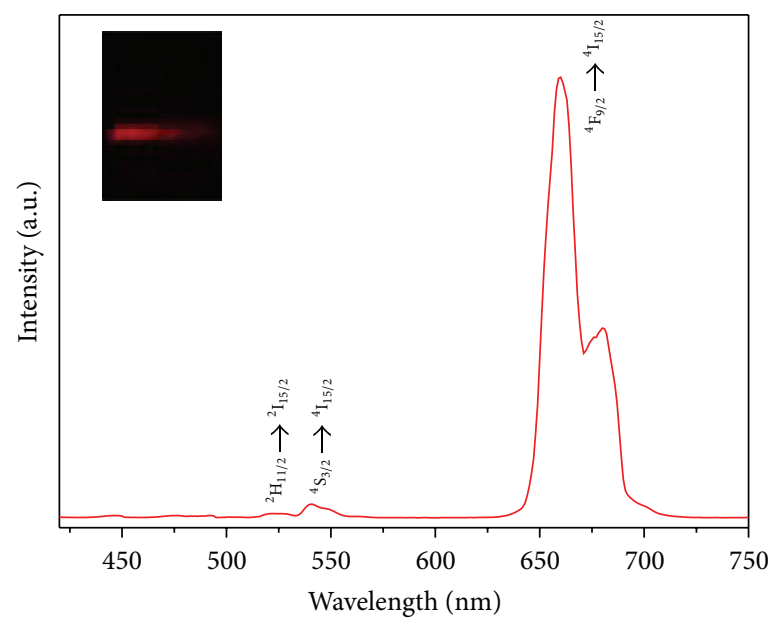

(a)

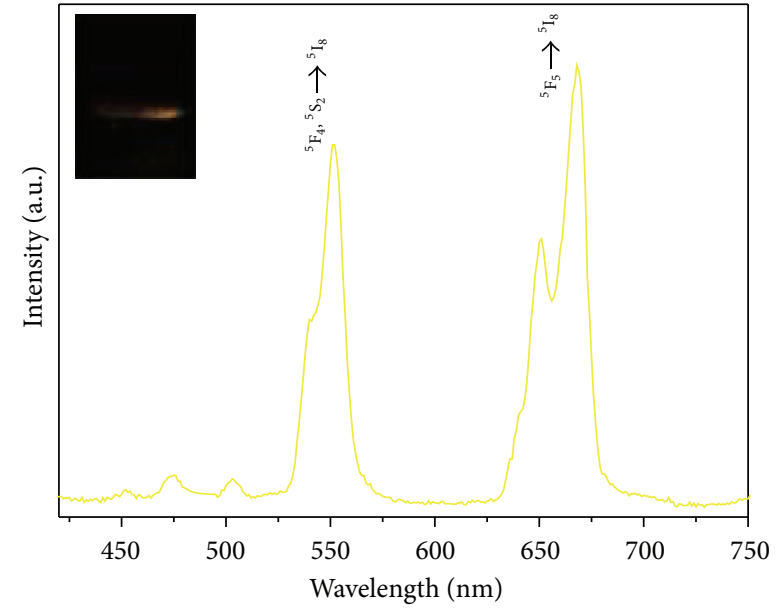

(b)

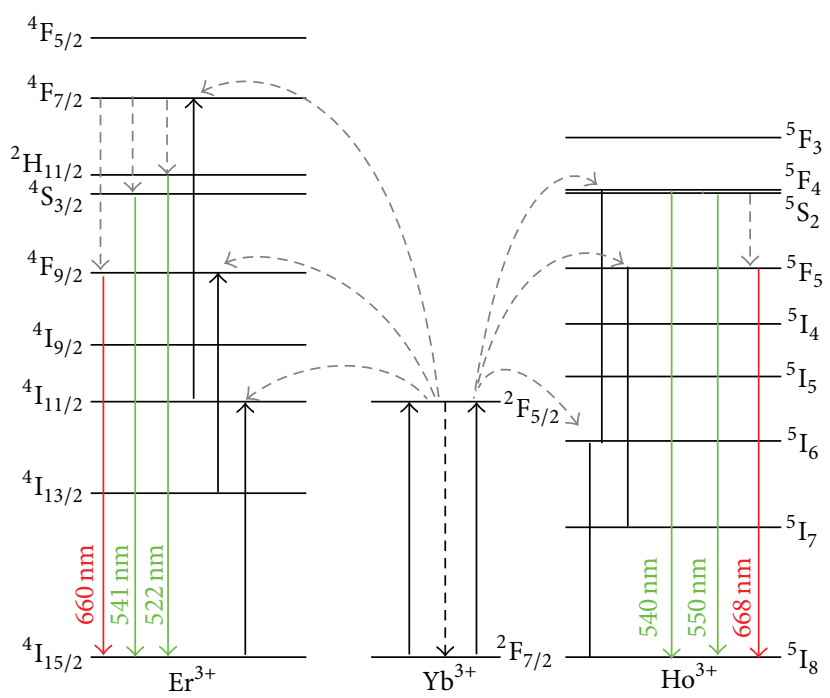

(c)

Figure 3: Upconversion luminescence spectra of $\mathrm{Y}_{2} \mathrm{O}_{3}$ nanoparticles doped with (a) $20 \% \mathrm{Yb}, 2 \%$ Er; (b) $20 \% \mathrm{Yb}, 2 \% \mathrm{Ho}$. (c) Simplified energy-level diagram of $\mathrm{Yb}^{3+} / \mathrm{Er}^{3+}$ and $\mathrm{Yb}^{3+} / \mathrm{Ho}^{3+}$ doped $\mathrm{Y}_{2} \mathrm{O}_{3}$ samples. The insets of (a) and (b) are the corresponding digital photographs of the water solutions of these nanoparticles.

emission of the $\mathrm{Ho}^{3+}$ ion is stronger than the ratio of green to red emission of $\mathrm{Er}^{3+}$. The insets of Figures 3(a) and 3(b) show the corresponding digital photographs of the water solution of the $\mathrm{Y}_{2} \mathrm{O}_{3}: \mathrm{Yb} / \mathrm{Er}$ and $\mathrm{Y}_{2} \mathrm{O}_{3}: \mathrm{Yb} / \mathrm{Ho}$, respectively. As demonstrated, the eye-visible red and yellow light can be readily observed.

To further reveal the UC multicolor output, we have calculated the CIE chromaticity coordinates of $\mathrm{Y}_{2} \mathrm{O}_{3}: \mathrm{Yb}^{3+} / \mathrm{Er}^{3+}$ and $\mathrm{Y}_{2} \mathrm{O}_{3}: \mathrm{Yb}^{3+} / \mathrm{Ho}^{3+}$. As shown in Figure 4, the chromaticity coordinates for $\mathrm{Y}_{2} \mathrm{O}_{3}: \mathrm{Yb}^{3+} / \mathrm{Er}^{3+}(X=0.6611, Y=0.3357)$ (Figure 4, point a) and $\mathrm{Y}_{2} \mathrm{O}_{3}: \mathrm{Yb}^{3+} / \mathrm{Ho}^{3+}(X=0.3884, \mathrm{Y}=$ 0.6026 ) (Figure 4 , point $\mathrm{b}$ ) are fallen into the red and yellow region, respectively, which is consistent with the results of the UC spectra and the digital photographs. The CIE diagram indicates that the UC colors including strong red and yellow can be obtained via co-doping $\mathrm{Yb}^{3+} / \mathrm{Er}^{3+}$ and $\mathrm{Yb}^{3+} / \mathrm{Ho}^{3+}$ in $\mathrm{Y}_{2} \mathrm{O}_{3}$ host material, respectively.

\section{Conclusions}

In summary, we have successfully synthesized sphericallike cubic phase $\mathrm{Y}_{2} \mathrm{O}_{3}$ nanoparticles with tunable multicolor UC emissions by using facile hydrothermal method. On the basis of the analysis of the XRD and TEM, the as-prepared $\mathrm{Y}(\mathrm{OH})_{3}: \mathrm{Yb} / \mathrm{Er}$ nanocrystals are composed of nanosheet and frizzy nanosheet and then the $\mathrm{Y}_{2} \mathrm{O}_{3}: \mathrm{Yb} / \mathrm{Er}$ nanoparticles with a quasispherical cubic phase structure were obtained by calcining precursor. Under the excitation of the $980 \mathrm{~nm}$ laser, multicolor visible emissions including strong red and yellow can be obtained via co-doping $\mathrm{Yb}^{3+} / \mathrm{Er}^{3+}$ and $\mathrm{Yb}^{3+} / \mathrm{Ho}^{3+}$ 


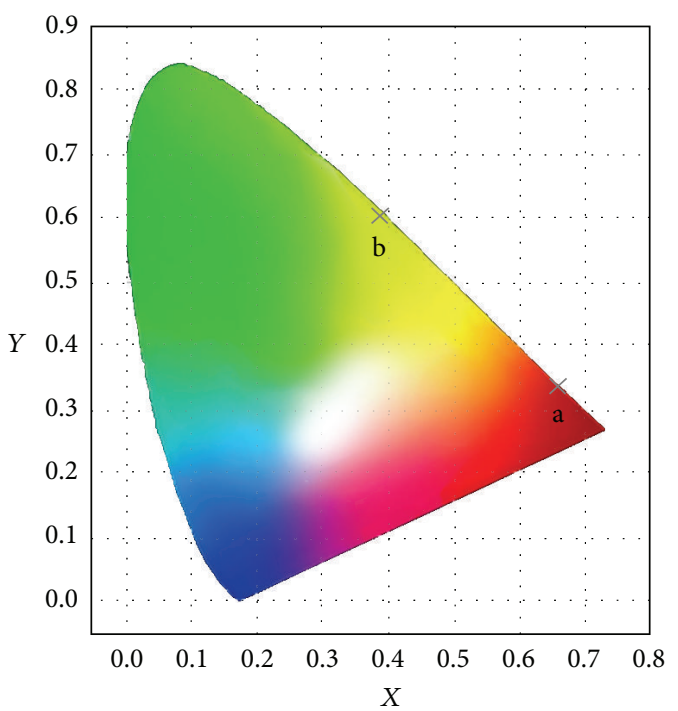

FIgURE 4: The CIE chromaticity diagram of $\mathrm{Y}_{2} \mathrm{O}_{3}$ nanoparticles doped with (a) 20\% Yb, 2\% $\operatorname{Er}(0.6611,0.3357)$; (b) 20\% Yb, $2 \%$ Ho $(0.3884,0.6026)$.

in $\mathrm{Y}_{2} \mathrm{O}_{3}$ host material, respectively. These UC nanoparticles with multicolors suggest that they have potential application in color displays and biolabels.

\section{Acknowledgments}

This work was supported by the National Natural Science Foundation of China (nos. 51102202 and 91230116), Specialized research Fund for the Doctoral Program of Higher Education of China (no. 20114301120006), Hunan Provincial Natural Science Foundation of China (Nos. 12JJ4056 and 13JJ1017), the Scientific Foundation of Ministry of Education (212119), and Scientific Research Fund of Hunan Provincial Education Department (13B062).

\section{References}

[1] F. Auzel, "Upconversion and anti-stokes processes with $\mathrm{f}$ and d ions in solids," Chemical Reviews, vol. 104, no. 1, pp. 139-174, 2004.

[2] J. F. Suyver, A. Aebischer, D. Biner et al., "Novel materials doped with trivalent lanthanides and transition metal ions showing near-infrared to visible photon upconversion," Optical Materials, vol. 27, no. 6, pp. 1111-1130, 2005.

[3] H. B. Wang, Z. G. Yi, L. Rao, H. R. Liu, and S. J. Zeng, "High quality multi-functional $\mathrm{NaErF}_{4}$ nanocrystals: structurecontrolled synthesis, phase-induced multi-color emissions and tunable magnetic properties," Journal of Materials Chemistry C, vol. 1, no. 35, pp. 5520-5526, 2013.

[4] T. Hase, T. Kano, E. Nakazawa, and H. Yamamoto, "Phosphor materials for cathode-ray tubes," in Advances in Electronics and Electron Physics, W. H. Peter, Ed., vol. 79, pp. 271-373, Academic Press, 1990.

[5] F. Vetrone, J.-C. Boyer, J. A. Capobianco, A. Speghini, and M. Bettinelli, "A spectroscopic investigation of trivalent lanthanide doped $\mathrm{Y}_{2} \mathrm{O}_{3}$ nanocrystals," Nanotechnology, vol. 15, no. 1, pp. 7581, 2004.

[6] R. Deng, X. Xie, M. Vendrell, Y.-T. Chang, and X. Liu, "Intracellular glutathione detection using $\mathrm{MnO}_{2}$-nanosheet-modified upconversion nanoparticles," Journal of the American Chemical Society, vol. 133, no. 50, pp. 20168-20171, 2011.

[7] Q. Liu, M. Chen, Y. Sun et al., "Multifunctional rare-earth selfassembled nanosystem for tri-modal upconversion luminescence/fluorescence/positron emission tomography imaging," Biomaterials, vol. 32, no. 32, pp. 8243-8253, 2011.

[8] H. R. Liu, W. Lu, H. B. Wang et al., "Simultaneous synthesis and amine-functionalization of single-phase $\mathrm{BaYF}_{5}: \mathrm{Yb} / \mathrm{Er}$ nanoprobe for dual-modal in vivo upconversion fluorescence and long-lasting X-ray computed tomography imaging," Nanoscale, vol. 5, no. 13, pp. 6023-6029, 2013.

[9] J. A. Capobianco, J. C. Boyer, F. Vetrone, A. Speghini, and M. Bettinelli, "Optical spectroscopy and upconversion studies of $\mathrm{Ho}^{3+}$-doped bulk and nanocrystalline $\mathrm{Y}_{2} \mathrm{O}_{3}$," Chemistry of Materials, vol. 14, no. 7, pp. 2915-2921, 2002.

[10] S. J. Zeng, M. K. Tsang, C. F. Chan, K. L. Wong, and J. H. Hao, "PEG modified $\mathrm{BaGdF}_{5}: \mathrm{Yb} / \mathrm{Er}$ nanoprobes for multi-modal upconversion fluorescent, in vivo X-ray computed tomography and biomagnetic imaging," Biomaterials, vol. 33, no. 36, pp. 9232-9238, 2012.

[11] J. McKittrick, L. E. Shea, C. F. Bacalski, and E. J. Bosze, "Influence of processing parameters on luminescent oxides produced by combustion synthesis," Displays, vol. 19, no. 4, pp. $169-172,1999$.

[12] S. Zeng, J. Xiao, Q. Yang, and J. Hao, "Bi-functional $\mathrm{NaLuF}_{4}: \mathrm{Gd}^{3+} / \mathrm{Yb}^{3+} / \mathrm{Tm}^{3+}$ nanocrystals: structure controlled synthesis, near-infrared upconversion emission and tunable magnetic properties," Journal of Materials Chemistry, vol. 22, no. 19, pp. 9870-9874, 2012.

[13] G.-Y. Adachi and N. Imanaka, "The binary rare earth oxides," Chemical Reviews, vol. 98, no. 4, pp. 1479-1514, 1998.

[14] S. F. Lim, R. Riehn, W. S. Ryu et al., "In vivo and scanning electron microscopy imaging of upconverting nanophosphors in Caenorhabditis elegans," Nano Letters, vol. 6, no. 2, pp. 169$174,2006$.

[15] T. R. Hinklin, S. C. Rand, and R. M. Laine, "Transparent, polycrystalline upconverting nanoceramics: towards 3-D displays," Advanced Materials, vol. 20, no. 7, pp. 1270-1273, 2008.

[16] R. Si, Y.-W. Zhang, H.-P. Zhou, L.-D. Sun, and C.-H. Yan, "Controlled-synthesis, self-assembly behavior, and surfacedependent optical properties of high-quality rare-earth oxide nanocrystals," Chemistry of Materials, vol. 19, no. 1, pp. 18-27, 2007.

[17] Y. C. Cao, "Synthesis of square gadolinium-oxide nanoplates," Journal of the American Chemical Society, vol. 126, no. 24, pp. 7456-7457, 2004.

[18] H. Wang, M. Uehara, H. Nakamura, M. Miyazaki, and H. Maeda, "Synthesis of well-dispersed $\mathrm{Y}_{2} \mathrm{O}_{3}$ :Eu nanocrystals and self-assembled nanodisks using a simple non-hydrolytic route," Advanced Materials, vol. 17, no. 20, pp. 2506-2509, 2005.

[19] R. Si, Y.-W. Zhang, L.-P. You, and C.-H. Yan, "Rare-earth oxide nanopolyhedra, nanoplates, and nanodisks," Angewandte Chemie-International Edition, vol. 44, no. 21, pp. 3256-3260, 2005.

[20] D. K. Williams, B. Bihari, B. M. Tissue, and J. M. McHale, "Preparation and fluorescence spectroscopy of bulk monoclinic $\mathrm{Eu}^{3+}: \mathrm{Y}_{2} \mathrm{O}_{3}$ and comparison to $\mathrm{Eu}^{3+}: \mathrm{Y}_{2} \mathrm{O}_{3}$ nanocrystals," Journal of Physical Chemistry B, vol. 102, no. 6, pp. 916-920, 1998. 
[21] N. Niu, P. P. Yang, F. He et al., "Tunable multicolor and bright white emission of one-dimensional $\mathrm{NaLuF}_{4}: \mathrm{Yb}^{3+}, \mathrm{Ln}^{3+}$ ( $\mathrm{Ln}$ $=\mathrm{Er}, \mathrm{Tm}, \mathrm{Ho}, \mathrm{Er} / \mathrm{Tm}, \mathrm{Tm} / \mathrm{Ho}$ ) microstructures," Journal of Materials Chemistry, vol. 22, no. 21, pp. 10889-10899, 2012.

[22] G. Ren, S. Zeng, and J. Hao, “Tunable multicolor upconversion emissions and paramagnetic property of monodispersed bifunctional lanthanide-doped $\mathrm{NaGdF}_{4}$ nanorods," Journal of Physical Chemistry C, vol. 115, no. 41, pp. 20141-20147, 2011.

[23] F. Wang and X. Liu, "Upconversion multicolor fine-tuning: visible to near-infrared emission from lanthanide-doped $\mathrm{NaYF}_{4}$ nanoparticles," Journal of the American Chemical Society, vol. 130, no. 17, pp. 5642-5643, 2008.

[24] J.-C. Boyer, F. Vetrone, L. A. Cuccia, and J. A. Capobianco, "Synthesis of colloidal upconverting $\mathrm{NaYF}_{4}$ nanocrystals doped with $\mathrm{Er}^{3+}, \mathrm{Yb}^{3+}$ and $\mathrm{Tm}^{3+}, \mathrm{Yb}^{3+}$ via thermal decomposition of lanthanide trifluoroacetate precursors," Journal of the American Chemical Society, vol. 128, no. 23, pp. 7444-7445, 2006.

[25] G. Glaspell, J. Anderson, J. R. Wilkins, and M. S. El-Shall, "Vapor phase synthesis of upconverting $\mathrm{y}_{2} \mathrm{O}_{3}$ nanocrystals doped with $\mathrm{Yb}^{3+}, \mathrm{Er}^{3+}, \mathrm{Ho}^{3+}$, and $\mathrm{Tm}^{3+}$ to generate red, green, blue, and white light," Journal of Physical Chemistry C, vol. 112, no. 30, pp. 11527-11531, 2008.

[26] F. Zhang and D. Zhao, "Synthesis of uniform rare earth fluoride $\left(\mathrm{NaMF}_{4}\right)$ nanotubes by in Situ ion exchange from their hydroxide $\left[\mathrm{M}(\mathrm{OH})_{3}\right]$ parents," ACS Nano, vol. 3, no. 1, pp. 159$164,2009$.

[27] X. Wang and Y. Li, "Synthesis and characterization of lanthanide hydroxide single-crystal nanowires," Angewandte ChemieInternational Edition, vol. 41, no. 24, pp. 4790-4793, 2002.

[28] X. Teng, Y. H. Zhu, W. Wei et al., "Lanthanide-doped $\mathrm{Na}_{x} \mathrm{ScF}_{3+} \mathrm{X}$ nanocrystals: crystal structure evolution and multicolor tuning," Journal of the American Chemical Society, vol. 134, no. 20, pp. 8340-8343, 2012.

[29] Y. Li, J. Zhang, Y. Luo, X. Zhang, Z. Hao, and X. Wang, "Color control and white light generation of upconversion luminescence by operating dopant concentrations and pump densities in $\mathrm{Yb}^{3+}, \mathrm{Er}^{3+}$ and $\mathrm{Tm}^{3+}$ tri-doped $\mathrm{Lu}_{2} \mathrm{O}_{3}$ nanocrystals," Journal of Materials Chemistry, vol. 21, no. 9, pp. 2895-2900, 2011.

[30] E. W. Barrera, M. C. Pujol, F. Díaz et al., "Emission properties of hydrothermal $\mathrm{Yb}^{3+}, \mathrm{Er}^{3+}$ and $\mathrm{Yb}^{3+}, \mathrm{Tm}^{3+}$-codoped $\mathrm{Lu}_{2} \mathrm{O}_{3}$ nanorods: upconversion, cathodoluminescence and assessment of waveguide behavior," Nanotechnology, vol. 22, no. 7, Article ID 075205, pp. 1-15, 2011. 

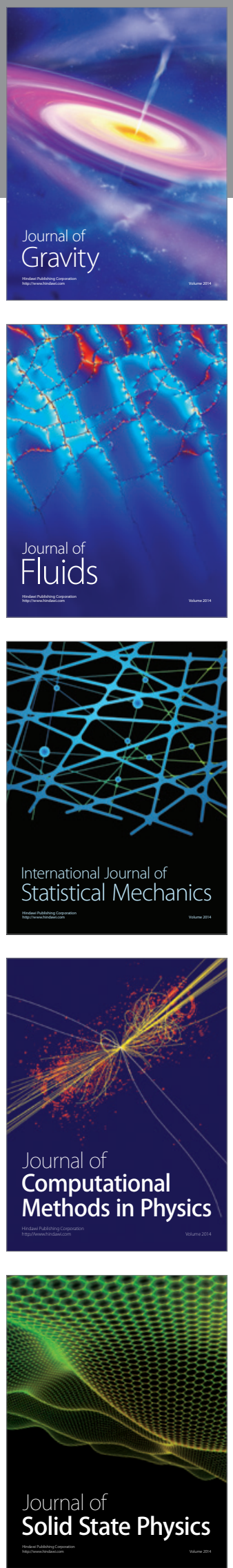

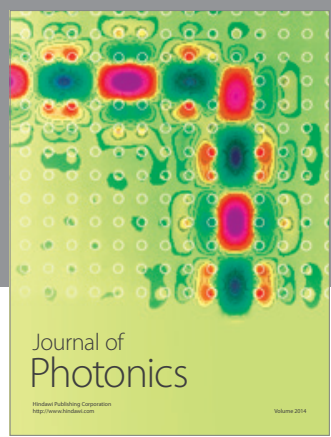

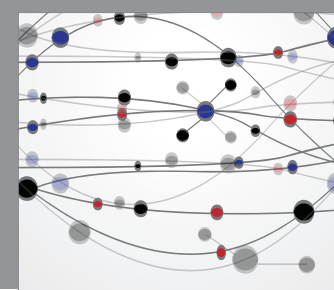

The Scientific World Journal

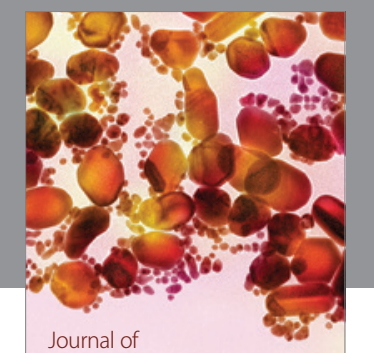

Soft Matter
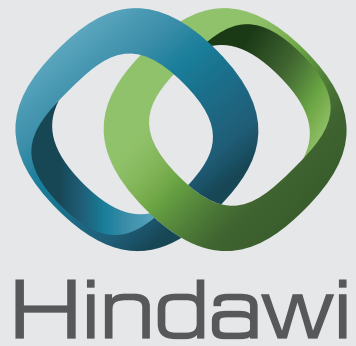

Submit your manuscripts at

http://www.hindawi.com
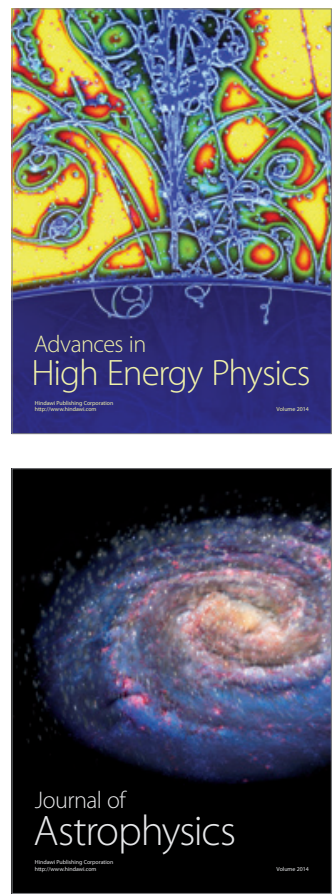
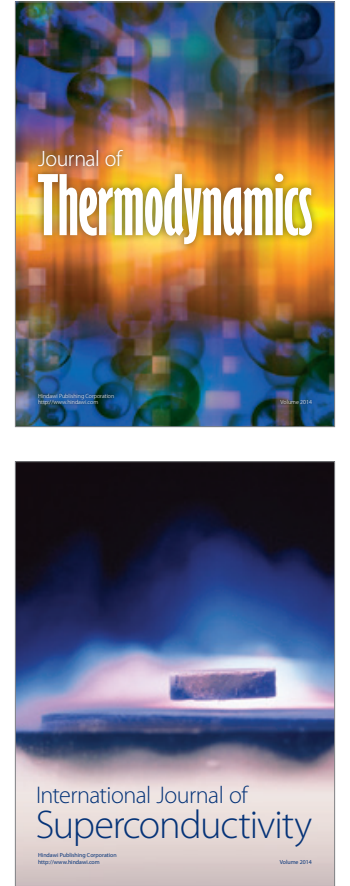
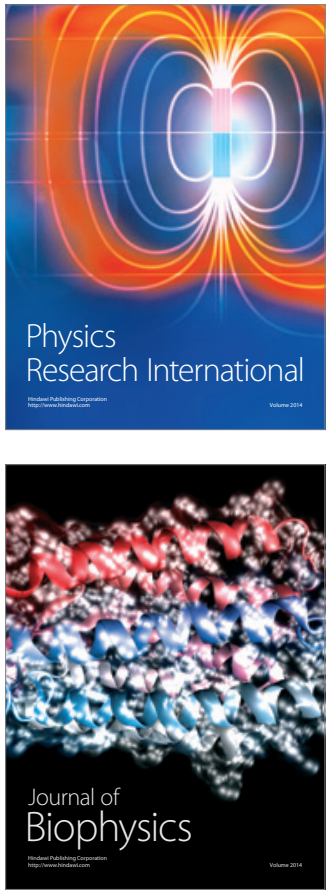
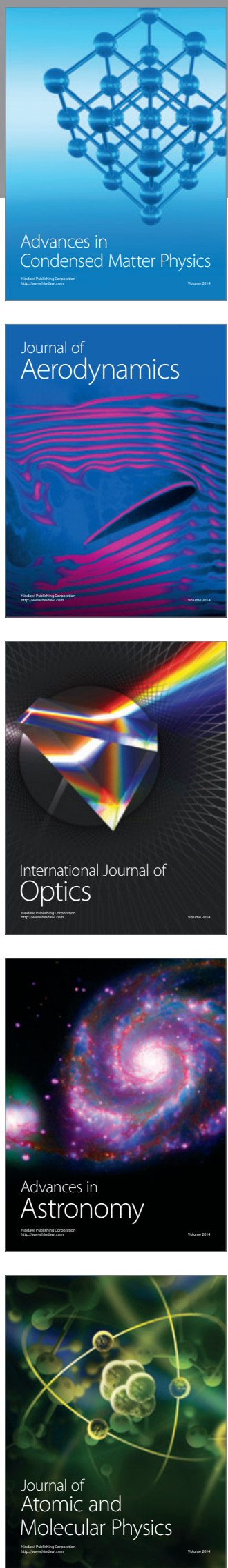